\title{
Multi-Temporal Landsat Images and Ancillary Data for Land Use/Cover Change (LULCC) Detection in the Southwest of Burkina Faso, West Africa
}

\section{Benewinde J-B. Zoungrana ${ }^{1, *}$, Christopher Conrad ${ }^{2}$, Leonard K. Amekudzi ${ }^{3}$, Michael Thiel ${ }^{2}$, Evariste Dapola Da ${ }^{4}$, Gerald Forkuor ${ }^{5}$ and Fabian Löw ${ }^{2}$}

1 Department of Civil Engineering, Kwame Nkrumah University of Science and Technology, University Post Office Box PMB, Kumasi, Ghana

2 Remote Sensing Unit at the Institute of Geography and Geology, University of Würzburg, Oswald-Külpe-Weg 86, 97074 Würzburg, Germany;

E-Mails: christopher.conrad@uni-wuerzburg.de (C.C.); michael.thiel@uni-wuerzburg.de (M.T.); fabian.loew@uni-wuerzburg.de (F.L.)

3 Department of Physics, Kwame Nkrumah University of Science and Technology, University Post Office Box PMB, Kumasi, Ghana; E-Mail: leonard.amekudzi@gmail.com

4 Department of Geography, University of Ouagadougou, 03 B.P. 7021 Ouagadougou, Burkina Faso; E-Mail: evaristeda@gmail.com

5 Competence Center, West African Science Service Center on Climate Change and Adapted Land Use, Ouagadougou BP 9507, Burkina Faso; E-Mail: gerald.forkuor@uni-wuerzburg.de

* Author to whom correspondence should be addressed; E-Mail: beneboscoh@gmail.com; Tel.: +226-76-271-220 or +226-73-768-903.

Academic Editors: Dengsheng Lu, Guomo Zhou, Conghe Song, Guangxing Wang, Ioannis Gitas and Prasad S. Thenkabail

Received: 1 July 2015 / Accepted: 7 September 2015 / Published: 18 September 2015

\begin{abstract}
Accurate quantification of land use/cover change (LULCC) is important for efficient environmental management, especially in regions that are extremely affected by climate variability and continuous population growth such as West Africa. In this context, accurate LULC classification and statistically sound change area estimates are essential for a better understanding of LULCC processes. This study aimed at comparing mono-temporal and multi-temporal LULC classifications as well as their combination with ancillary data and to determine LULCC across the heterogeneous landscape of southwest Burkina Faso using accurate classification results. Landsat data (1999, 2006 and 2011) and ancillary data served
\end{abstract}


as input features for the random forest classifier algorithm. Five LULC classes were identified: woodland, mixed vegetation, bare surface, water and agricultural area. A reference database was established using different sources including high-resolution images, aerial photo and field data. LULCC and LULC classification accuracies, area and area uncertainty were computed based on the method of adjusted error matrices. The results revealed that multi-temporal classification significantly outperformed those solely based on mono-temporal data in the study area. However, combining mono-temporal imagery and ancillary data for LULC classification had the same accuracy level as multi-temporal classification which is an indication that this combination is an efficient alternative to multi-temporal classification in the study region, where cloud free images are rare. The LULCC map obtained had an overall accuracy of $92 \%$. Natural vegetation loss was estimated to be $17.9 \% \pm 2.5 \%$ between 1999 and 2011 . The study area experienced an increase in agricultural area and bare surface at the expense of woodland and mixed vegetation, which attests to the ongoing deforestation. These results can serve as means of regional and global land cover products validation, as they provide a new validated data set with uncertainty estimates in heterogeneous ecosystems prone to classification errors.

Keywords: multi-temporal images; mono-temporal image; ancillary data; LULCC; Burkina Faso; West Africa

\section{Introduction}

Remote sensing plays an important role in the management of the earth's surface by providing spatio-temporal information on land use/cover (e.g., water, forest, bare area, and cropland). Change in land use/cover (LULC) affects the global environment [1], its biodiversity [2], local, regional and global climate $[3,4]$, and also can accelerate, among others land degradation, which reduces ecosystem services and functions [5]. Monitoring land use/cover change (LULCC) is, therefore, relevant for sustainable landscape and environmental management. For instance, in regions like West Africa, where LULC is known to change rapidly [6], regular map updates could lead to better estimation of deforestation and land degradation rates, which are key components of the UN REDD (Reducing Emissions from Deforestation and Forest Degradation) program and UNCCD (United Nation Convention to Combat Desertification) strategy “Zero Net Land Degradation”, respectively.

Remote sensing provides an effective means for mapping LULC, especially over large areas [7]. Different types of classifications have been applied for LULC mapping [8-11]. Some of these classifications are based on mono-temporal image (e.g., [12,13]), multi-temporal images (e.g., [10,14]), or in combination with ancillary data (e.g., $[11,15,16])$ such as biophysical variables (e.g., elevation, slope and soil types). Mono-temporal classification is widely used in literature (e.g., [6,12,17,18]); this analysis focuses on a single date image for LULC mapping. The processing of single date image is faster as compared to multi-temporal classification. In multi-temporal classification, bands from more than one date, season, or year are combined and classified [19]. This approach involves the use of more images, which increases 
processing time. Multi-temporal classification has been used to classify the LULC of various landscapes (e.g., $[10,14,20])$.

A comparison of mono-temporal and multi-temporal classifications in different areas revealed contradictory results. For instance, in two states in the United States of America (USA), Lunetta and Balogh [10] used single date Landsat image against two dates of imagery and found that the latter increased wetlands identification accuracy from $69 \%$ to $88 \%$. Key et al. [14] also noticed a positive effect of multi-temporal classification for discriminating individual tree species in a temperate hardwood forest (West Virginia University forest). Contrary to the aforementioned studies, Langley et al. [19] compared single date and multi-temporal satellite image classifications in semi-arid grassland and found out that single date classification produced more satisfactory results than multi-temporal classification. The integration of ancillary data with mono-temporal image has been found in some places suitable for improving LULC classification accuracy (e.g., [11,15]).

Although mono-temporal and multi-temporal classifications as well as the addition of ancillary data have been compared in elsewhere, such investigations remain rare in West Africa, especially in the Sudanese savannah zone. In addition, determining an efficient LULC mapping method is crucial for performing accurate post-classification change analysis and to monitor environmental degradation in this region, which is particularly exposed to effects of climate change and population growth. Furthermore, an accurate LULCC map could be an efficient decision-making support tool for mitigating carbon emission and for proper environmental change management, such as forest cover restoration through reforestation campaigns.

LULCC assessment in West Africa is challenging, as the region lacks atmospherically undisturbed and cloud free satellite images, which is a limiting factor for LULC mapping. Beside, lack of ground truth information for past years limits assessments of historical LULC (e.g., [21]) as well as validation of LULCC map (e.g., [6,22,23]).

The present study aimed at comparing mono-temporal and multi-temporal LULC classifications as well as their combination with ancillary data and to determine LULCC across the heterogeneous landscape of southwest Burkina Faso using accurate classification results.

\section{Materials and Method}

\subsection{Study Area}

The study area is located in the Black Volta basin of Burkina Faso with an area of about $5120 \mathrm{~km}^{2}$ (Figure 1) and belongs to the South-Sudanese climatic zone that is characterized by two main seasons. The rainy season extends from May to October, and the dry season occurs from November to April. The average monthly temperature ranges from $26{ }^{\circ} \mathrm{C}$ to $32{ }^{\circ} \mathrm{C}$, and the average annual rainfall in the period 1981-2012 was estimated to be $862.87 \mathrm{~mm}$ based on the data collected from the national direction of meteorology of Burkina Faso. Rainfall is marked by high inter-annual variability, and the vegetation is Sudanese savannah of which dominant woody species are Gardenia sp, Combretum micranthum, Parkia biglobosa, Vitellaria paradoxa, Bombax costatum, Berlinia grandifotia, among others.

The main livelihood activity of the local population is agriculture, which is characterized by low inputs (e.g., fertilizers) with slash and burn being the frequently applied farming practice [6]. According to Reenberg et al. [24], the typical agricultural practice is small-scale subsistence farming on rainfed 
fields, while the main crop productions are cotton and cereals (e.g., sorghum, maize and millet). Rice is cultivated as dry-rice in topographic depression or as irrigated wet-rice close to lakes and dammed-up rivers [13].

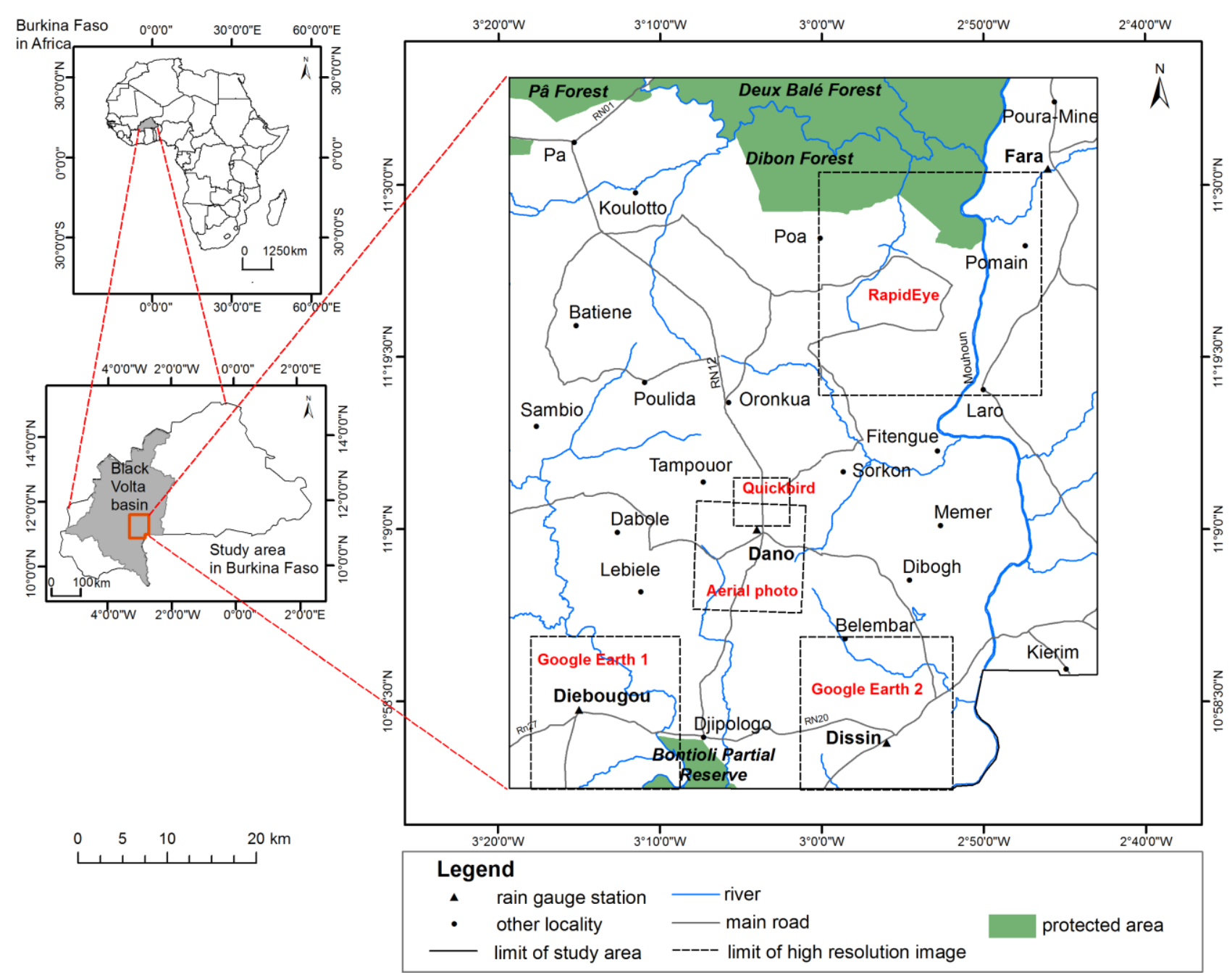

Figure 1. Situation of the study area.

\subsection{Data and Pre-Processing}

\subsubsection{Landsat Images}

Landsat TM data $(30 \mathrm{~m} \times 30 \mathrm{~m}$ resolution, scene 196/052) were used for LULC classification. In total, ten monthly images were downloaded from United States Geological Survey (USGS) website for the years 1999, 2006 and 2011 (Table 1) using a criterion of cloud cover less than 10\%. Five Landsat bands were considered in this study: blue $(0.45-0.52 \mu \mathrm{m})$, green $(0.52-0.60 \mu \mathrm{m})$, red $(0.63-0.69 \mu \mathrm{m})$, near infrared $(0.76-0.90 \mu \mathrm{m})$ and middle infrared $(1.55-1.75 \mu \mathrm{m})$.

The Landsat data were calibrated and corrected to remove atmospheric influences. Firstly, the digital numbers (DN) values of the TM images were calibrated into radiance based on information from the meta data files provided by USGS (e.g., sun elevation, acquisition date). Afterwards, the radiance data were converted to surface reflectance using the ENVI 5 FLAASH (Fast Line-of-sight Atmospheric Analysis of Spectral Hypercubes) module, which has shown to be efficient for satellite images 
atmospheric correction (e.g., [25]). This module requires information such as sensor altitude, initial visibility, atmospheric model, aerosol model, flight date, pixel size, and scene center location [26]. Some of these parameters were obtained from meta data files, while others were already included into the module such as atmospheric and aerosol models which were set to tropical and rural, respectively, during the atmospheric correction process to match with the study area environment.

Image-to-image co-registration was performed in order to ensure good alignment of pixels in the respective images. A root mean square error of less than one pixel was achieved for all the co-registrations. The images were already georeferenced to the Universal Transverse Mercator (UTM) projection WGS84 zone 30 north.

Table 1. Landsat TM images of 2011, 2006 and 1999.

\begin{tabular}{ccc}
\hline $\mathbf{2 0 1 1}$ & $\mathbf{2 0 0 6}$ & $\mathbf{1 9 9 9}$ \\
\hline 3 March & 31 October & 20 October \\
6 May & 16 November & 14 February \\
7 June & 18 December & - \\
9 July & - & - \\
29 October & - & - \\
\hline
\end{tabular}

\subsubsection{Environmental Ancillary Data}

Ancillary data were also included in the LULC classification process (Table 2): slope, elevation, soil types and geomorphology. Slope and elevation were derived from version 2 of Digital Elevation Model (DEM) of ASTER, which has a spatial resolution of $30 \mathrm{~m} \times 30 \mathrm{~m}$. The DEM was georeferenced to UTM WGS84 zone 30 north. Vector layers (shapefiles) for geomorphology and soil types were obtained from the National Soil Office of Burkina Faso (BUNASOL) at a scale of 1/500,000. They highlighted different geomorphological units and soil types found in the study area. The shapefiles were projected to UTM WGS84 zone 30 north, then rasterized and resampled to $30 \mathrm{~m} \times 30 \mathrm{~m}$ using ArcGIS 10.1.

Table 2. Ancillary data used in LULC classification.

\begin{tabular}{cccc}
\hline Ancillary data & Source & Description & resolution \\
\hline Elevation & ASTER & Height & $30 \mathrm{~m} \times 30 \mathrm{~m}$ \\
Slope & ASTER & degree & $30 \mathrm{~m} \times 30 \mathrm{~m}$ \\
Soil & BUNASOL-BF & Soil types & $30 \mathrm{~m} \times 30 \mathrm{~m}$ \\
Geomorphology & BUNASOL-BF & geomorphological units & $30 \mathrm{~m} \times 30 \mathrm{~m}$ \\
\hline
\end{tabular}

\subsubsection{Reference Data Sources}

High-resolution images (Table 3) and field data were used to collect LULC reference samples to train and validate the Landsat images classifications. The high-resolution images were acquired as close as possible to the acquisition dates of the Landsat TM images. RapidEye image (from April 2011) was collected from the RapidEye Science Archive Team (RESA) of the German Aerospace Center (DLR) at level 3A (i.e., orthorectified with a spatial resolution of $5 \mathrm{~m} \times 5 \mathrm{~m}$ and georeferenced to UTM projection). In addition, Quickbird image $(2.4 \mathrm{~m} \times 2.4 \mathrm{~m})$ was acquired from October 2012, and scanned aerial photo (June 1999) was obtained from the National Geographic Institute of Burkina Faso (IGB) with a 
resolution of $2.3 \mathrm{~m} \times 2.3 \mathrm{~m}$. High-resolution images of Google Earth (from October 2006 and November 2007) were also used in this research. Apart from the RapidEye image that was already corrected, the other spatial data were geometrically adjusted (co-registration) to the Landsat images and georeferenced to UTM WGS84 zone 30 north.

A field campaign was conducted in October 2013 to collect LULC ground truth samples with a handheld Global Positioning Systems (GPS) using the projection system UTM WGS84 zone 30 north. LULC areas that remained stable since 2011 were sampled based on local population knowledge. Five broad LULC classes were identified (Table 4) using a modified LULC classification scheme of the FAO [27]: Woodland, bare surface, agricultural area, water and mixed vegetation. Homogeneous areas of $30 \times 30 \mathrm{~m}$ were surveyed for each LULC (to match Landsat pixel), and the coordinate of the center recorded. In total, 150 samples were recorded across the study area.

Table 3. High-resolution images used in the analysis.

\begin{tabular}{ccccc}
\hline Images & Date & Resolution & Extent & \% of study area covered \\
\hline RapidEye & April 2011 & $5 \mathrm{~m} \times 5 \mathrm{~m}$ & $625 \mathrm{~km}^{2}$ & 12.20 \\
Quickbird & October 2012 & $2.4 \mathrm{~m} \times 2.4 \mathrm{~m}$ & $25.7 \mathrm{~km}^{2}$ & 0.50 \\
Aerial photo & June 1999 & $2.3 \mathrm{~m} \times 2.3 \mathrm{~m}$ & $188 \mathrm{~km}^{2}$ & 3.70 \\
Google Earth image 1 & November 2007 & $2.4 \mathrm{~m} \times 2.4 \mathrm{~m}$ & $306.9 \mathrm{~km}^{2}$ & 6.00 \\
Google Earth image 2 & October 2006 & $2.4 \mathrm{~m} \times 2.4 \mathrm{~m}$ & $309.8 \mathrm{~km}^{2}$ & 6.05 \\
\hline
\end{tabular}

Table 4. Adapted LULC classification scheme, modified from FAO [27].

\begin{tabular}{|c|c|c|}
\hline \multirow{2}{*}{$\begin{array}{c}\text { Non-Modified } \\
\text { Level } 1 \\
\end{array}$} & \multicolumn{2}{|l|}{ Modified } \\
\hline & Level 2 & Adopted LULC classes \\
\hline Vegetated & $\begin{array}{c}\text { Woodland } \\
\text { Mixture of grasses, shrubs and trees } \\
\text { Cultivated area }\end{array}$ & $\begin{array}{c}\text { Woodland } \\
\text { Mixed vegetation } \\
\text { Agricultural area }\end{array}$ \\
\hline \multirow{2}{*}{ Non-vegetated } & $\begin{array}{l}\text { Bare land } \\
\text { Built up } \\
\text { Tarred road } \\
\text { Rock }\end{array}$ & Bare surface \\
\hline & $\begin{array}{c}\text { Rivers } \\
\text { Artificial water bodies } \\
\text { Lakes }\end{array}$ & Water \\
\hline
\end{tabular}

\subsection{LULC Classification}

\subsubsection{Image Combinations}

In order to assess the classification of mono-temporal and multi-temporal satellite data as well as their combination with ancillary data, four spatial data set combinations were produced using Landsat images and ancillary data (Table 5). These images combinations are: (1) mono-temporal image; (2) mono-temporal image plus ancillary data; (3) multi-temporal images; and (4) multi-temporal images plus ancillary data. For the combination of mono-temporal image with ancillary data (Table 5, column 2), only the image 
that produced the highest overall accuracy amongst all mono-temporal classifications (Table 5, column 1) was selected.

Table 5. Different approaches of image combinations used for the year 2011.

\begin{tabular}{ccccc}
\hline & $\begin{array}{c}\text { Mono-Temporal } \\
\text { Image }\end{array}$ & $\begin{array}{c}\text { Mono-Temporal Image } \\
\text { Plus Ancillary Data }\end{array}$ & $\begin{array}{c}\text { Multi-Temporal } \\
\text { Images }\end{array}$ & $\begin{array}{c}\text { Multi-Temporal Images } \\
\text { Plus Ancillary Data }\end{array}$ \\
\hline $\begin{array}{c}\text { Landsat } \\
\text { bands }\end{array}$ & $\begin{array}{c}\text { Five images } \\
\text { (October, July, June, } \\
\text { May and March) }\end{array}$ & $\begin{array}{c}\text { Image which achieved the } \\
\text { highest accuracy in mono- } \\
\text { temporal classification }\end{array}$ & $\begin{array}{c}\text { Five images } \\
\text { (October, July, June, } \\
\text { May and March) }\end{array}$ & $\begin{array}{c}\text { Five images (October, July, } \\
\text { June, May and March) }\end{array}$ \\
\hline \multirow{4}{*}{$\begin{array}{c}\text { Elevation } \\
\text { data }\end{array}$} & & Slope & Elevation \\
& & Geomorphology & & Slope \\
Soil types & & Geomorphology \\
& & & & Soil types \\
\hline
\end{tabular}

\subsubsection{Classification Algorithm: Random Forest Classification Algorithm}

Supervised classifications of the Landsat images were performed using Breiman's [28] non-parametric Random Forest (RF) classifier. RF is a machine learning algorithms [29] that can incorporate diverse sources of data (e.g., biophysical and remotely sensed data) [30], and it was found more accurate than other classifiers such as maximum likelihood classification (e.g., [31,32]), support vector machine (e.g., [31]) and neural networks (e.g., [33]).

$\mathrm{RF}$ is an ensemble of classification trees in which each tree contributes with a single vote for the assignment of the most frequent class to the input vector $(\mathrm{X}), \hat{C}_{r f}^{B}=$ majority vote $\left\{\hat{C}_{b}(X)\right\}_{1}^{B}[28,34]$, where $\hat{C}_{b}(X)$ is the class prediction of the bth random forest tree, and $B$ the total number of trees.

In fact, RF collects different subsets of training data to grow the trees (Ntree) using bagging [35] which is a technique used for training data creation by randomly resampling the original dataset with replacement (i.e., with no deletion of the data selected from the input sample for generating the next subset) $[34,36]$. A second random sampling is operated by RF to select a subset of predictive variables (Mtry) for the division of every node, which reduces the generalization error [29,37]. This randomness included in RF process decreases the correlation between trees in the forest and increases accuracy [38]. RF also computes the contribution of each variable to the classification using Mean Decrease Gini (MDG) and Mean Decrease Accuracy (MDA). However, Nicodemus [39] noticed that MDG is sensitive to within-predictors correlation and differences in category frequencies, while MDA is robust to these data characteristics.

Field data (only for 2011) and visual interpretation of the high-resolution images provide the possibility to collect a first set of LULC truth points (for each years) to train the RF classifier. Polygons of homogeneous pixels were drawn around each truth point for each LULC class and saved as vector layer of training areas. Landsat pixels that overlap the training areas were then used to train the RF classifier using $\mathrm{R}$ statistical software. The number of trees built was set to 800 , and the number of selected variables at each node split was, by default, the square root of the total number of variables in each image combination. 


\subsection{LULCC Mapping: Post Classification Change Detection}

Pixel-based post-classification change detection was performed using the classified maps of 1999 and 2011. Post-classification change detection consists in comparing individual LULC maps from two different periods in order to determine change areas. It emphasizes on "from to" change detection technique, which provides a change matrix and enables tracking the trajectory of each pixel between the two time steps of observation. In the present study, the post-classification change detection was performed in ArcGIS 10.1 where the LULC maps of 1999 and 2011 were combined into one raster file using the function "combine". This enabled the detection of 25 LULC conversions or LULCC classes using the attribute table of the produced raster. However, four generalized categories of LULCC classes were considered: stable natural vegetation (SNV), natural vegetation loss (NVL), stable non-natural vegetation (SNNV), and other change (OC). Based on a new field created in the attribute table of the combined raster file, the four LULCC classes were assigned to each pixel following the rules shown in Table 6 below.

Table 6. LULC conversions included in the four LULCC classes between 1999 and 2011.

\begin{tabular}{|c|c|c|c|c|}
\hline Name & $\begin{array}{c}\text { Stable Natural } \\
\text { Vegetation } \\
\end{array}$ & $\begin{array}{c}\text { Natural Vegetation } \\
\text { Loss } \\
\end{array}$ & $\begin{array}{c}\text { Stable non-Natural } \\
\text { Vegetation } \\
\end{array}$ & Other Change \\
\hline \multirow{3}{*}{$\begin{array}{l}\text { Change } \\
\text { classes }\end{array}$} & Stable woodland & $\begin{array}{l}\text { Woodland to other } \\
\text { LULC unless mixed } \\
\text { vegetation }\end{array}$ & Stable agricultural area & $\begin{array}{c}\text { Agricultural area to all } \\
\text { other LULC }\end{array}$ \\
\hline & $\begin{array}{l}\text { Stable mixed } \\
\text { vegetation } \\
\text { Woodland to } \\
\text { mixed vegetation } \\
\text { Mixed vegetation } \\
\text { to woodland }\end{array}$ & $\begin{array}{l}\text { Mixed vegetation to } \\
\text { other LULC unless } \\
\text { woodland }\end{array}$ & Stable bare surface & $\begin{array}{c}\text { Bare surface to all other } \\
\text { LULC }\end{array}$ \\
\hline & & & Stable water area & Water to all other LULC \\
\hline
\end{tabular}

\subsection{Accuracy and Area Assessment}

\subsubsection{Sampling Design}

The sampling design is the protocol for selecting the subset of spatial units that will form the basis of the accuracy assessment [40,41]. In this study, pixels were used as spatial units $(30 \mathrm{~m} \times 30 \mathrm{~m})$. Stratified random sampling was applied for collecting a second set of reference points to test RF classifications and validate the LULCC map; this is because the statistics computed in this study were based on the adjusted error matrix that requests a probability sampling for collecting reference data [42]. Stratified random sampling is a probability sampling design and a key element of a statistically rigorous assessment [41]. It enables statistical inference for computing estimates with confidence intervals.

Here, the different LULC and LULCC classes were considered as strata. Stratification is conducted when the strata are of interest for reporting results (e.g., accuracy and LULC class area), and to improve the precision of the accuracy and area estimates [40]. The strata sample allocation can be done either by 
equal sample size (same sample size for each class) or by proportional sample size (sample proportional to the spatial extent of each class in the map). The first method favors user's accuracy against overall and producer's accuracies [43], while, in the second method, the standard errors of estimating producer's and overall accuracies become smaller as compared to equal allocation [40]. In order to take advantage of both sample allocation methods, the recommendation of Olofsson et al. [40] to increase the sample size of the rarer classes was followed in this study.

\subsubsection{Response Design}

The response design is the protocol for determining the reference LULC classification of a sampling unit [41]. The high-resolution images were used as reference data (Table 3).

For each year, the portions of the classified Landsat data that overlapped the high-resolution images were extracted and converted to polygon vector layer (in ArcGIS 10.1) from which the RF training areas were excluded. Each class was isolated as an individual vector layer based on which a set of randomly selected pixels were generated for each stratum (class). Each pixel received a LULC label by visual interpretation of the high-resolution images. The labels of each reference pixels on the maps and the high-resolution images were then compared to produce error matrices. Altogether, 371, 328 and 345 pixels were selected as samples for the years 2011, 2006 and 1999, respectively. The samples allocated to each stratum are shown in Table 7.

For the LULCC of the period 1999-2011, the overlapping area between LULCC map, aerial photo of 1999 and high-resolution images of 2011 were considered for reference pixels collection following the same procedure as above. However, Landsat images (1999 and 2011) were included especially for LULCC classes that were underrepresented in the high-resolution images. In all, 300 LULCC reference pixels were selected based on the classes established in Section 2.4. The numbers of samples are given in Table 8. Finally, the labels of the reference pixels on the change map and also on the reference images of 1999 and 2011 were compared to build an error matrix.

Table 7. Sample size allocated to each LULC class in 1999, 2006 and 2011.

\begin{tabular}{cccc}
\hline & \multicolumn{3}{c}{ Sample Allocated } \\
\hline LULC classes (strata) & 2011 & 2006 & 1999 \\
Water & 42 & 40 & 42 \\
Woodland & 100 & 97 & 111 \\
Bare surfaces & 59 & 45 & 45 \\
Mixed vegetation & 75 & 78 & 89 \\
Agric. Area & 95 & 68 & 58 \\
Total column & 371 & 328 & 345 \\
\hline
\end{tabular}

Table 8. Sample size allocated to each LULCC class.

\begin{tabular}{cc}
\hline LULCC Classes (strata) & Sample Allocated \\
\hline Stable natural vegetation & 125 \\
Natural vegetation loss & 56 \\
Stable non-natural vegetation & 42 \\
Other change & 77 \\
Total & 300 \\
\hline
\end{tabular}




\subsubsection{Analysis}

Accuracy assessment

In order to determine the accuracy of a classified map with $q$ categories, an error matrix is constructed [44]. Following the suggestions of Olofsson et al. [42] for assessing the accuracy of LULCC maps based on stratified random sampling strategies and pixel-based classifications, the error matrices of both LULCC and LULC classification were adjusted by the area of each category on the maps, and error matrices based on area proportions $\left(\hat{P}_{i j}\right)$ were produced:

$$
\hat{P}_{i j}=W_{i} \frac{n_{i j}}{n_{i+}}
$$

where $W_{i}$ is the proportion of area of category $i$ in the map, $n_{i j}$ is the number of samples mapped as $i$ and belonging to category $j$ in the reference data, $n_{i+}$ is the number of samples mapped as category $i$ in the map. In the adjusted error matrix (Table 9), each cell element $\hat{P}_{i j}$ indicates the probability that a randomly selected area is classified under category $i$ in the image and under category $j$ in the reference data [45].

Table 9. Adjusted error matrix of estimated area proportions.

\begin{tabular}{|c|c|c|c|c|c|c|c|c|}
\hline \multicolumn{9}{|c|}{ Reference } \\
\hline \multirow{8}{*}{$\frac{\tilde{\sigma}}{\sum^{2}}$} & & 1 & 2 & $\ldots$ & $j$ & $\ldots$ & $q$ & Total \\
\hline & 1 & $\hat{P}_{11}$ & $\hat{P}_{12}$ & $\ldots$ & $\hat{P}_{1 j}$ & & $\hat{P}_{1 q}$ & $\hat{P}_{1+}$ \\
\hline & 2 & $\hat{P}_{21}$ & $\hat{P}_{22}$ & $\ldots$ & & $\ldots$ & & $\hat{P}_{2+}$ \\
\hline & $\vdots$ & $\vdots$ & $\vdots$ & $\vdots$ & $\vdots$ & $\vdots$ & $\vdots$ & $\vdots$ \\
\hline & $i$ & $\hat{P}_{i 1}$ & $\hat{P}_{i 2}$ & $\ldots$ & $\hat{P}_{i j}$ & $\ldots$ & $\hat{P}_{i q}$ & $\hat{P}_{i+}$ \\
\hline & $\vdots$ & $\vdots$ & $\vdots$ & $\vdots$ & & $\vdots$ & $\vdots$ & $\vdots$ \\
\hline & $q$ & $\hat{P}_{q 1}$ & $\hat{P}_{q 2}$ & $\ldots$ & $\hat{P}_{q j}$ & $\ldots$ & $\hat{P}_{q q}$ & $\hat{P}_{q+}$ \\
\hline & Total & $\hat{P}_{+1}$ & $\hat{P}_{+2}$ & $\ldots$ & $\hat{P}_{+j}$ & $\ldots$ & $\hat{P}_{+q}$ & 1 \\
\hline
\end{tabular}

Based on this new error matrix, accuracies (overall, user's and producer's) were calculated. The overall accuracy $(\hat{O})$ indicates the overall proportion of area correctly classified. It is the sum of $\hat{p}_{i i}$ of the adjusted error matrix diagonal.

$$
\hat{O}=\sum_{i=1}^{q} \hat{P}_{i i}
$$

User's accuracy $\left(\widehat{U}_{i}\right)$ of class $i$ is the proportion of the area mapped as class $i$ that has reference class $i$, and producer's accuracy $\left(\hat{P}_{j}\right)$ of class $j$ is the proportion of the area of reference class $\mathrm{j}$ that is mapped as class j. Both accuracies were computed according to Equations (3) and (4), respectively.

$$
\begin{gathered}
\widehat{U}_{i}=\frac{\hat{P}_{i i}}{\widehat{P}_{i+}} \\
\hat{P}_{j}=\frac{\hat{P}_{j j}}{\hat{P}_{+j}}
\end{gathered}
$$

Classification types performance 
McNemar's test was used to evaluate the performance of multi-temporal and mono-temporal classification as well as their integration with ancillary data. It is a non-parametric test that is more precise and sensitive than the Kappa z-test [46]. McNemar's test evaluates the difference between paired proportions. Here, the test is based on a pair of confusion matrices of correctly and wrongly classified reference samples. It produces a chi-square $\left(\chi^{2}\right)$ statistics that is computed by Equation (5). The difference between two classification approaches is significant when the $p$-value is less than 0.05 .

$$
\chi^{2}=\frac{\left(f_{12}-f_{21}\right)^{2}}{\left(f_{12}+f_{21}\right)}
$$

where $f_{12}$ indicates the number of cases that are wrongly classified by approach 2 , but correctly classified by approach 1 , and $f_{21}$ is the number of cases that are correctly classified by approach 2 , but wrongly classified by approach 1 .

Area estimates and uncertainty

In accordance with the systematic approach suggested by Olofsson et al. [42], the adjusted error matrix was used to compute an area estimator based on the proportion of the area of category $j$. Equation (6) gives the area of category $\mathrm{j}\left(\hat{A}_{j}\right)$.

$$
\hat{A}_{j}=A_{t o t} \times \hat{P}_{+j}
$$

where $A_{\text {tot }}$ is the total area, and

$$
\hat{P}_{+j}=\sum_{i=1}^{q} W_{i} \frac{n_{i j}}{n_{i+}}
$$

This area estimator is an error-adjusted estimator of area that includes the area of map omission error of category $j$ and removes the area of map commission error [42]. Its standard error $S\left(\hat{A}_{j}\right)$ was computed as follows.

$$
S\left(\hat{A}_{j}\right)=A_{t o t} \times S\left(\hat{P}_{+j}\right)
$$

where the standard error for the stratified estimator of proportion of area $S\left(\hat{P}_{+j}\right)$ is computed as:

$$
S\left(\hat{P}_{+j}\right)=\sqrt{\sum_{i=1}^{q} \frac{W_{i} \hat{P}_{i k-} \hat{P}_{i k}^{2}}{n_{i+}-1}}
$$

The use of $\widehat{P}_{+j}$ (estimated from the reference samples) instead of $\widehat{P}_{i+}$ (map areas) is because it allows the assessment of uncertainty of the area estimates in the form of sampling variability that can be computed as confidence interval. For $\hat{A}_{j}$ the approximate $95 \%$ confidence interval $(C I)$ was derived as:

$$
C I=\hat{A}_{j} \pm z \times S\left(\hat{A}_{j}\right)
$$

where $\mathrm{z}$ corresponds to the percentile from the curve of the standard normal distribution, and for $95 \%$ confidence, $\mathrm{z}=1.96$. 


\section{Results}

\subsection{Suitable Period for Mono-Temporal LULC Classification}

In order to detect the most adequate period to classify the observed LULC, the year 2011 was selected because it had images from dry season (March), early rainy season (May and June), mid rainy season (July) and late rainy season (October), which cover the entire vegetation period. The results of the mono-temporal RF classifications are shown in Figure 2, and it can be observed that there is an increase in overall, average user's and average producer's accuracies from March to October. Table 10 presents the pixels count error matrices obtained from the five mono-temporal classifications. Major confusions were recorded, for instance, between agricultural area and natural vegetation, agricultural area and bare surface and among natural vegetation types. The use of October image for classification outperformed all other mono-temporal attempts, because it reduced confusion between natural vegetation classes (Woodland and Mixed vegetation) and between agricultural area and natural vegetation, among others. The matrices clarify that at the end of the dry period (March) the class agriculture area seems to spectrally resemble other classes, which explains the aforementioned low accuracies obtained for that period. The main finding is that the LULC classification of the late rainy season images (e.g., October) performed better than those applied to images of the mid rainy, early rainy and dry seasons. Therefore, the mono-temporal image of October served as benchmark for assessing the effect of multi-temporal images and ancillary data on LULC classification.

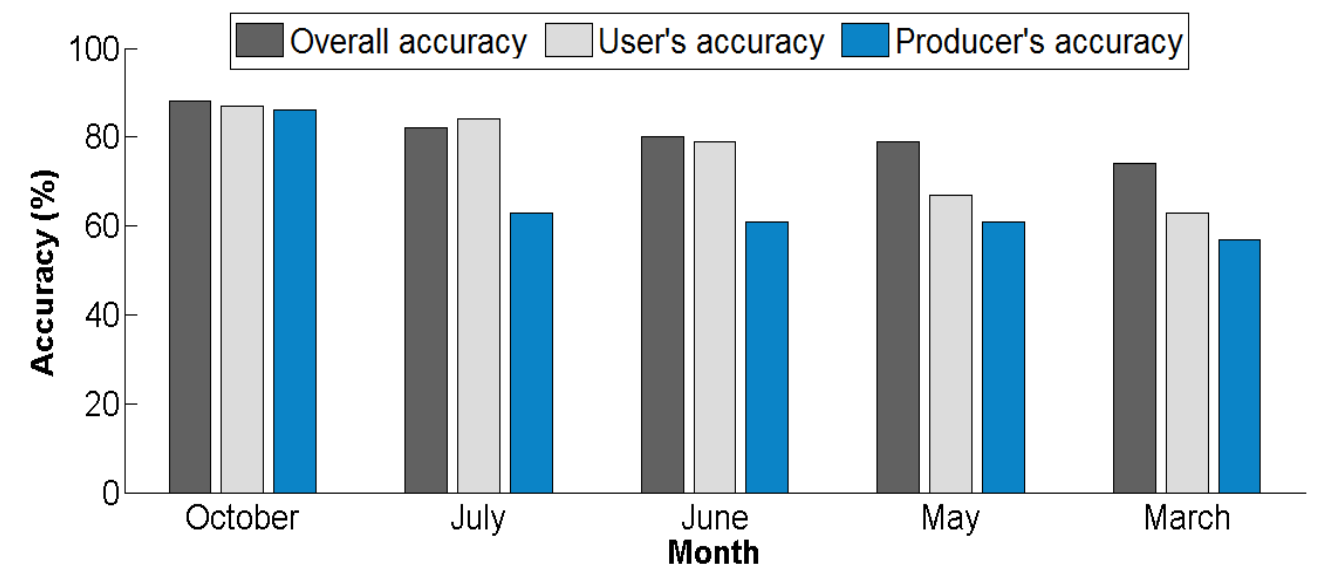

Figure 2. Overall, user's and producer's accuracies of the mono-temporal classifications of 2011 derived from adjusted error matrix. User's and producer's accuracies are averages of the class-wise assessments.

\subsection{LULC Classification Accuracies According to Images Combinations}

The results presented in Table 11 show that mono-temporal classification (of the best performing data set, October) had the lowest accuracy among the four combinations of images. In contrast to the optimal mono-temporal approach, multi-temporal classification improved the overall accuracy from $88 \%$ to $94 \%$, the average user's from $87 \%$ to $93 \%$, and the average producer's from $86 \%$ to $91 \%$. The incorporation of ancillary data has also positively influenced the LULC discrimination. Indeed, their integration with mono-temporal image (October) yielded an overall accuracy comparable to the use of 
multi-temporal data (94\%). There was also an improvement in average user's accuracy ( $87 \%$ to $93 \%)$ and average producer's accuracy ( $86 \%$ to $91 \%$ ). However, the best performance in terms of the accuracy assessment was recorded by the combination of multi-temporal images and ancillary data, which produced the highest overall, average user's and average producer's accuracies with values of $95 \%, 95 \%$ and $92 \%$, respectively. This superiority of multi-temporal classification and the addition of ancillary data over mono-temporal classification is supported by the results of McNemar's test (Table 12). The test showed significant difference $(p<0.05)$ in LULC classifications produced by multi-temporal, mono-temporal plus ancillary data and multi-temporal plus ancillary data classifications over mono-temporal data. However, no significance difference was found between multi-temporal, mono-temporal plus ancillary data and multi-temporal plus ancillary data classifications.

The positive impact of multi-temporal images and ancillary data was also perceptible on each LULC class. The user's and producer's accuracies of each class, according to Tables 13 and 14, indicate that the discrimination of the individual LULC classes was improved with the use of multi-temporal images and the addition of ancillary data.

Table 10. Error matrices of mono-temporal LULC classifications of 2011, the values in all the tables refer to the numbers of pixels. 1: Water; 2: Woodland; 3: Bare surface; 4: Mixed vegetation; 5: Agricultural area.

\begin{tabular}{ccccccc}
\hline & \multicolumn{5}{c}{ March } & \\
\hline $\mathbf{1}$ & 1 & $\mathbf{2}$ & $\mathbf{3}$ & $\mathbf{4}$ & $\mathbf{5}$ & Total \\
$\mathbf{2}$ & 0 & 0 & 2 & 0 & 25 & 42 \\
$\mathbf{3}$ & 0 & 4 & 0 & 5 & 16 & 100 \\
$\mathbf{4}$ & 1 & 16 & 12 & 34 & 14 & 77 \\
$\mathbf{5}$ & 0 & 0 & 0 & 5 & 90 & 95 \\
Total & 16 & 99 & 49 & 51 & 156 & 371 \\
\hline & & & May & & & \\
\hline & $\mathbf{1}$ & $\mathbf{2}$ & $\mathbf{3}$ & $\mathbf{4}$ & $\mathbf{5}$ & Total \\
$\mathbf{1}$ & 13 & 0 & 16 & 0 & 13 & 42 \\
$\mathbf{2}$ & 3 & 91 & 0 & 3 & 3 & 100 \\
$\mathbf{3}$ & 0 & 2 & 44 & 5 & 8 & 59 \\
$\mathbf{4}$ & 0 & 20 & 4 & 39 & 12 & 75 \\
$\mathbf{5}$ & 1 & 4 & 2 & 5 & 83 & 95 \\
Total & 17 & 117 & 66 & 52 & 119 & 371 \\
\hline & & & June & & & \\
\hline & $\mathbf{1}$ & $\mathbf{2}$ & $\mathbf{3}$ & $\mathbf{4}$ & $\mathbf{5}$ & Total \\
$\mathbf{1}$ & 37 & 0 & 0 & 0 & 5 & 42 \\
$\mathbf{2}$ & 4 & 91 & 2 & 1 & 2 & 100 \\
$\mathbf{3}$ & 0 & 5 & 46 & 3 & 5 & 59 \\
$\mathbf{4}$ & 0 & 20 & 9 & 36 & 10 & 75 \\
$\mathbf{5}$ & 0 & 3 & 1 & 5 & 86 & 95 \\
Total & 41 & 119 & 58 & 45 & 108 & 371 \\
\hline & & & & & &
\end{tabular}


Table 10. Cont.

\begin{tabular}{|c|c|c|c|c|c|c|}
\hline \multicolumn{7}{|c|}{ July } \\
\hline & 1 & 2 & 3 & 4 & 5 & Total \\
\hline 1 & 42 & 0 & 0 & 0 & 0 & 42 \\
\hline 2 & 6 & 87 & 1 & 3 & 3 & 100 \\
\hline 3 & 0 & 6 & 46 & 2 & 5 & 59 \\
\hline 4 & 0 & 9 & 8 & 43 & 15 & 75 \\
\hline 5 & 0 & 2 & 1 & 0 & 92 & 95 \\
\hline Total & 48 & 104 & 56 & 48 & 115 & 371 \\
\hline \multicolumn{7}{|c|}{ October } \\
\hline & 1 & 2 & 3 & 4 & 5 & Total \\
\hline 1 & 40 & 2 & 0 & 0 & 0 & 42 \\
\hline 2 & 0 & 90 & 0 & 6 & 4 & 100 \\
\hline 3 & 0 & 0 & 48 & 6 & 5 & 59 \\
\hline 4 & 0 & 5 & 4 & 57 & 9 & 75 \\
\hline 5 & 0 & 0 & 0 & 5 & 90 & 95 \\
\hline Total & 40 & 97 & 52 & 74 & 108 & 371 \\
\hline
\end{tabular}

Table 11.Classification accuracy in $2011(\%)$ according to images combinations.

\begin{tabular}{cccc}
\hline Images Combinations & Overall Accuracy & Av. User's acc. & Av. Producer's Acc. \\
\hline Mono-temporal & 88 & 87 & 86 \\
Mono-temporal plus ancillary & 94 & 93 & 91 \\
Multi-temporal & 94 & 93 & 91 \\
Multi-temporal plus ancillary data & 95 & 95 & 92 \\
\hline
\end{tabular}

Table 12. McNemar's test results between image combinations.

\begin{tabular}{ccccc}
\hline & \multicolumn{4}{c}{ Mono-Temporal } \\
\cline { 2 - 5 } Multi-temporal & $\boldsymbol{f}_{\mathbf{1 2}}$ & $\boldsymbol{f}_{\mathbf{2 1}}$ & Chi-square & $p$-value \\
Mono-temporal plus ancillary data & 4 & 22 & 12.5 & 0.0004 \\
Multi-temporal plus ancillary data & 6 & 23 & 10 & 0.001 \\
& 1 & 19 & 16.2 & 0.00005 \\
\cline { 2 - 5 } & $\boldsymbol{f}_{\mathbf{1 2}}$ & $\boldsymbol{f}_{\mathbf{2 1}}$ & Chi-square & $p$-value \\
Multi-temporal & 6 & 7 & 0.08 & 0.8 \\
Multi-temporal plus ancillary data & 10 & 5 & 1.7 & 0.2 \\
\hline & \multicolumn{4}{c}{ Multi-temporal } \\
Multi-temporal plus ancillary data & $\boldsymbol{f}_{\mathbf{1 2}}$ & $\boldsymbol{f}_{\mathbf{2 1}}$ & Chi-square & $p$-value \\
& 8 & \multicolumn{4}{c}{2.3} & 0.1 \\
\hline
\end{tabular}

\subsection{Contribution of Remotely Sensed Bands and Ancillary Data to LULC Classification}

The contribution of the remotely sensed bands and ancillary data to LULC classification in the study area is shown in Figure 3, which highlights the mean decrease accuracy (MDA) score of each variable. This was computed by RF algorithm based on the classification of mono-temporal image plus ancillary data. In general, near infrared, middle infrared and elevation were the three most important variables for LULC 
classification. They are followed by geomorphology, red, green and blue bands, whereas slope and soil types were the least important variables. Among the four environmental data used in this research, elevation and geomorphology have more contributed to LULC discrimination compared to soil types and slope.

Table 13. LULC user's accuracy (\%) per image combination in 2011.

\begin{tabular}{cccccc}
\hline Classification Approach & Water & Woodland & $\begin{array}{c}\text { Bare } \\
\text { Surface }\end{array}$ & $\begin{array}{c}\text { Mixed } \\
\text { Vegetation }\end{array}$ & $\begin{array}{c}\text { Agricultural } \\
\text { Area }\end{array}$ \\
\hline Mono-temporal & 95 & 90 & 81 & 76 & 94 \\
Mono-temporal plus ancillary & 95 & 98 & 90 & 88 & 95 \\
Multi-temporal & 95 & 96 & 90 & 89 & 97 \\
Multi-temporal plus ancillary & 98 & 99 & 93 & 88 & 97 \\
\hline
\end{tabular}

Table 14. LULC producer's accuracy (\%) per image combination in 2011.

\begin{tabular}{cccccc}
\hline Classification Approach & Water & Woodland & $\begin{array}{c}\text { Bare } \\
\text { Surface }\end{array}$ & $\begin{array}{c}\text { Mixed } \\
\text { Vegetation }\end{array}$ & $\begin{array}{c}\text { Agricultural. } \\
\text { Area }\end{array}$ \\
\hline Mono-temporal & 100 & 96 & 66 & 81 & 85 \\
Mono-temporal plus ancillary & 100 & 100 & 69 & 92 & 93 \\
Multi-temporal & 100 & 100 & 71 & 92 & 93 \\
Multi-temporal plus ancillary & 100 & 98 & 69 & 94 & 97 \\
\hline
\end{tabular}

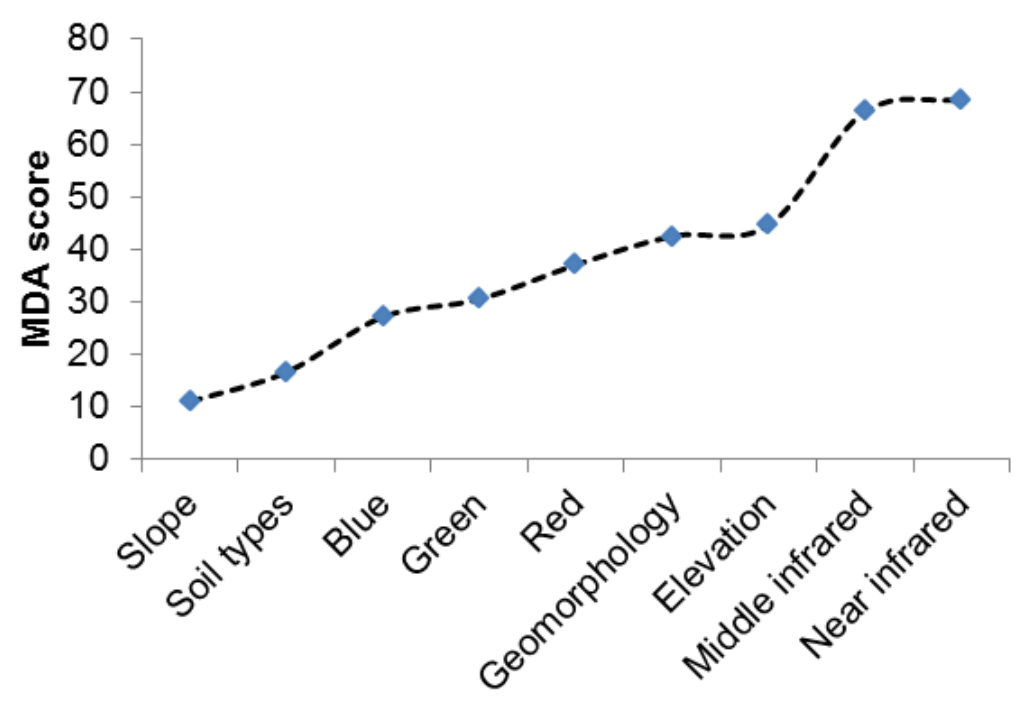

Figure 3. Remotely sensed bands and ancillary data contributions to LULC classification based on mean decrease accuracy (MDA) score of RF mono-temporal image plus ancillary data classification.

\subsection{The Dynamics of LULC in the Study Area over the Years 1999, 2006 and 2011}

In accordance with the results of the 2011 classifications, the combination of multi-temporal images and ancillary data was used to classify the images of 1999 and 2006. The monthly Landsat images of 1999 and 2006, specified in Table 1, were combined with ancillary data (Table 2), and the classification yielded 94\% (93\%) as overall accuracy for the LULC map of 1999 (2006). The distribution of each LULC area in 1999, 2006 and 2011 is presented in Tables 15-17, respectively. The mapped area is slightly different from 
the estimated area for all LULC classes. In all cases, it could be found within the confidence interval (95\%) around the estimated area indicating a high reliability of the produced maps [42].

Table 15. Proportion of LULC types in 1999.

\begin{tabular}{cccc}
\hline LULC & $\begin{array}{c}\text { Mapped } \\
\text { Area \% }\end{array}$ & $\begin{array}{c}\text { Estimated } \\
\text { Area \% }\end{array}$ & $\begin{array}{c}\text { Confidence } \\
\text { Interval \% }\end{array}$ \\
\hline Water & 1.7 & 1.7 & \pm 0.1 \\
Woodland & 41.5 & 40.1 & \pm 2.0 \\
Bare surface & 1.8 & 2.4 & \pm 1.0 \\
Mixed vegetation & 33.2 & 33.2 & \pm 2.3 \\
Agricultural area & 21.8 & 22.6 & \pm 2.3 \\
Total & 100 & 100 & \\
\hline
\end{tabular}

Table 16. Proportion of LULC types in 2006.

\begin{tabular}{cccc}
\hline LULC & $\begin{array}{c}\text { Mapped } \\
\text { Area \% }\end{array}$ & $\begin{array}{c}\text { Estimated } \\
\text { Area \% }\end{array}$ & $\begin{array}{c}\text { Confidence } \\
\text { Interval \% }\end{array}$ \\
\hline Water & 0.7 & 0.7 & \pm 0.04 \\
Woodland & 39 & 38.1 & \pm 1.3 \\
Bare surface & 1.8 & 2.9 & \pm 1.3 \\
Mixed vegetation & 32.5 & 32.3 & \pm 1.7 \\
Agricultural area & 26 & 26 & \pm 2.6 \\
Total & 100 & 100 & \\
\hline
\end{tabular}

Table 17. Proportion of LULC types in 2011.

\begin{tabular}{cccc}
\hline LULC & $\begin{array}{c}\text { Mapped } \\
\text { Area\% }\end{array}$ & $\begin{array}{c}\text { Estimated } \\
\text { Area \% }\end{array}$ & $\begin{array}{c}\text { Confidence } \\
\text { Interval \% }\end{array}$ \\
\hline Water & 0.2 & 0.2 & \pm 0.01 \\
Woodland & 35.3 & 36.4 & \pm 2.1 \\
Bare surface & 2.9 & 3.3 & \pm 1.4 \\
Mixed vegetation & 31.6 & 30.4 & \pm 1.3 \\
Agricultural area & 30 & 29.7 & \pm 1.6 \\
Total & 100 & 100 & \\
\hline
\end{tabular}

The results revealed that agricultural area and bare surface have increased in the study area at the expense of woodland and mixed vegetation, which decreased over the years. For instance, the proportion of agricultural area increased from $22.6 \% \pm 2.3 \%$ in 1999 to $26 \% \pm 2.6 \%$ in 2006 and further to $29.7 \% \pm 1.6 \%$ in 2011 . These dynamics are well captured in Figure 4, which highlights the expansion of agricultural area (in yellow) across the study area. Contrary, the areas of woodland and mixed vegetation, as observed in 1999, decreased in 2006 and 2011 (Tables 15-17). A decreasing trend was also observed for areas covered by water. 

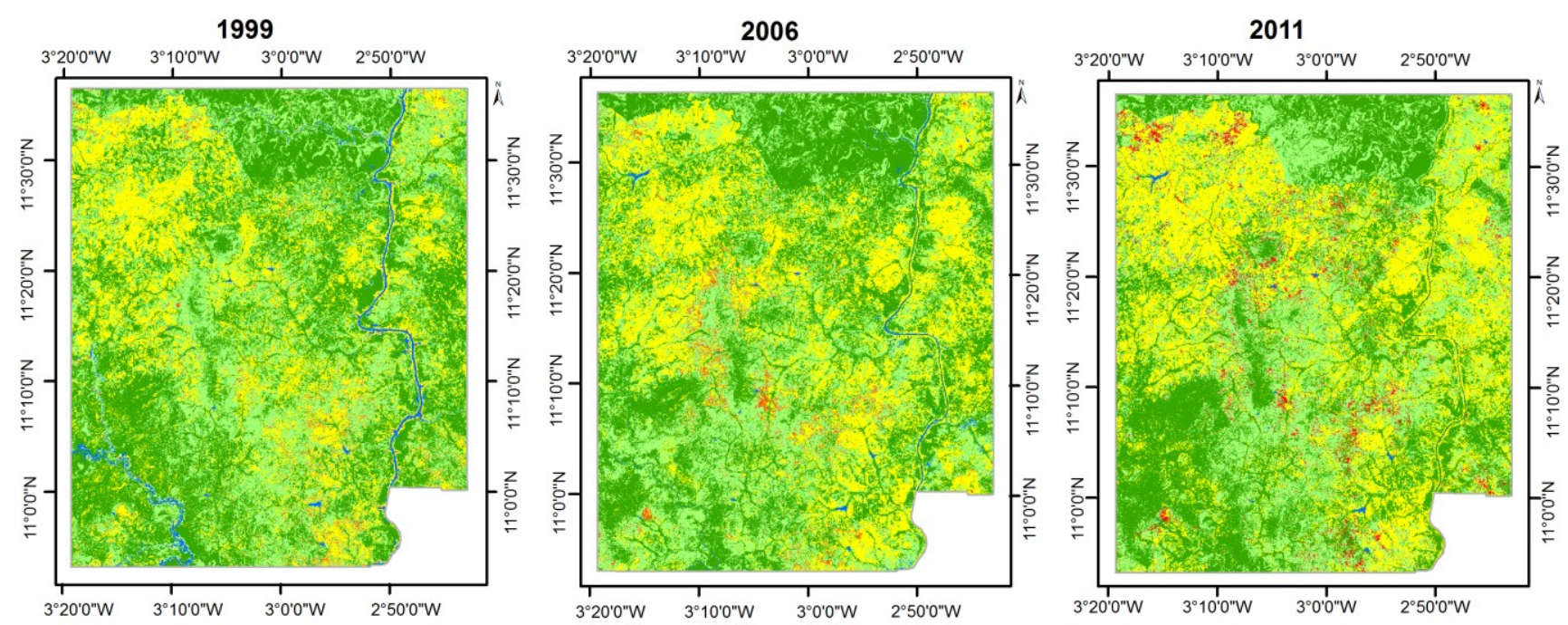

Legend
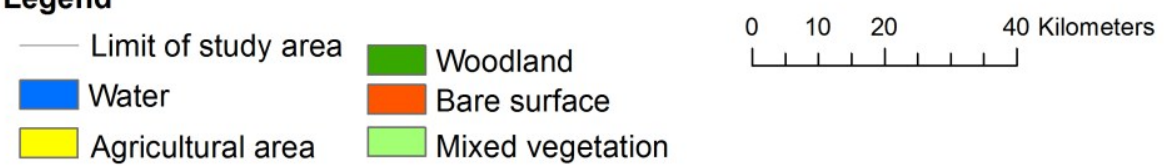

Figure 4. LULC spatial distribution in the study area in 1999, 2006 and 2011.

\subsection{LULCC in the Study Area between 1999 and 2011}

The adjusted error matrix of the LULCC map derived between 1999 and 2011 is given by Table 18 . The accuracy assessment returned an overall accuracy of $92 \%$, while the user's accuracy ranged from $86 \%$ to $95 \%$ and the producer's accuracy from $84 \%$ to $95 \%$.

Table 18. Adjusted error matrix of LULCC map between 1999 and 2011. SNV: stable natural vegetation; NVL: natural vegetation loss; SNNV: stable non-natural vegetation; OC: other change.

\begin{tabular}{ccccccc}
\hline & SNV & NVL & SNNV & OC & Total & User's (\%) \\
\hline SNV & 0.547 & 0.014 & 0 & 0.014 & 0.575 & 95 \\
NVL & 0.016 & 0.151 & 0.003 & 0.003 & 0.173 & 87 \\
SNNV & 0.004 & 0.01 & 0.129 & 0 & 0.143 & 90 \\
OC & 0.007 & 0.004 & 0.004 & 0.094 & 0.109 & 86 \\
Total & 0.574 & 0.179 & 0.136 & 0.111 & 1 & \\
Producer's (\%) & 95 & 84 & 95 & 85 & & 92 \\
\hline
\end{tabular}

Table 19 presents the estimated and the mapped LULCC areas. In this case also, the map area of each LULCC class fell within the computed confidence interval (95\%). Between 1999 and 2011, 57.4\% $\pm 2.7 \%$ of the study area was dominated by stable natural vegetation. Area under loss of natural vegetation represented $17.9 \% \pm 2.5 \%$. Stable non-natural vegetation and other change covered $13.6 \% \pm 1.5 \%$ and $11.1 \% \pm 1.9 \%$ of the study area, respectively. The distribution of the LULCC classes in the study area is shown in Figure 5 where most of the losses of natural vegetation are located in areas dominated by agriculture. 
Table 19. LULCC area between 1999 and 2011.

\begin{tabular}{cccc}
\hline & Map Area & \multicolumn{2}{c}{ Estimated Area } \\
\hline LULCC classes & $\%$ & $\%$ & Conf. interval (\%) \\
Stable natural vegetation & 57.5 & 57.4 & \pm 2.7 \\
Natural vegetation loss & 17.2 & 17.9 & \pm 2.5 \\
Stable non-natural vegetation & 14.3 & 13.6 & \pm 1.5 \\
Other change & 11 & 11.1 & \pm 1.9 \\
Total & 100 & 100 & \\
\hline
\end{tabular}

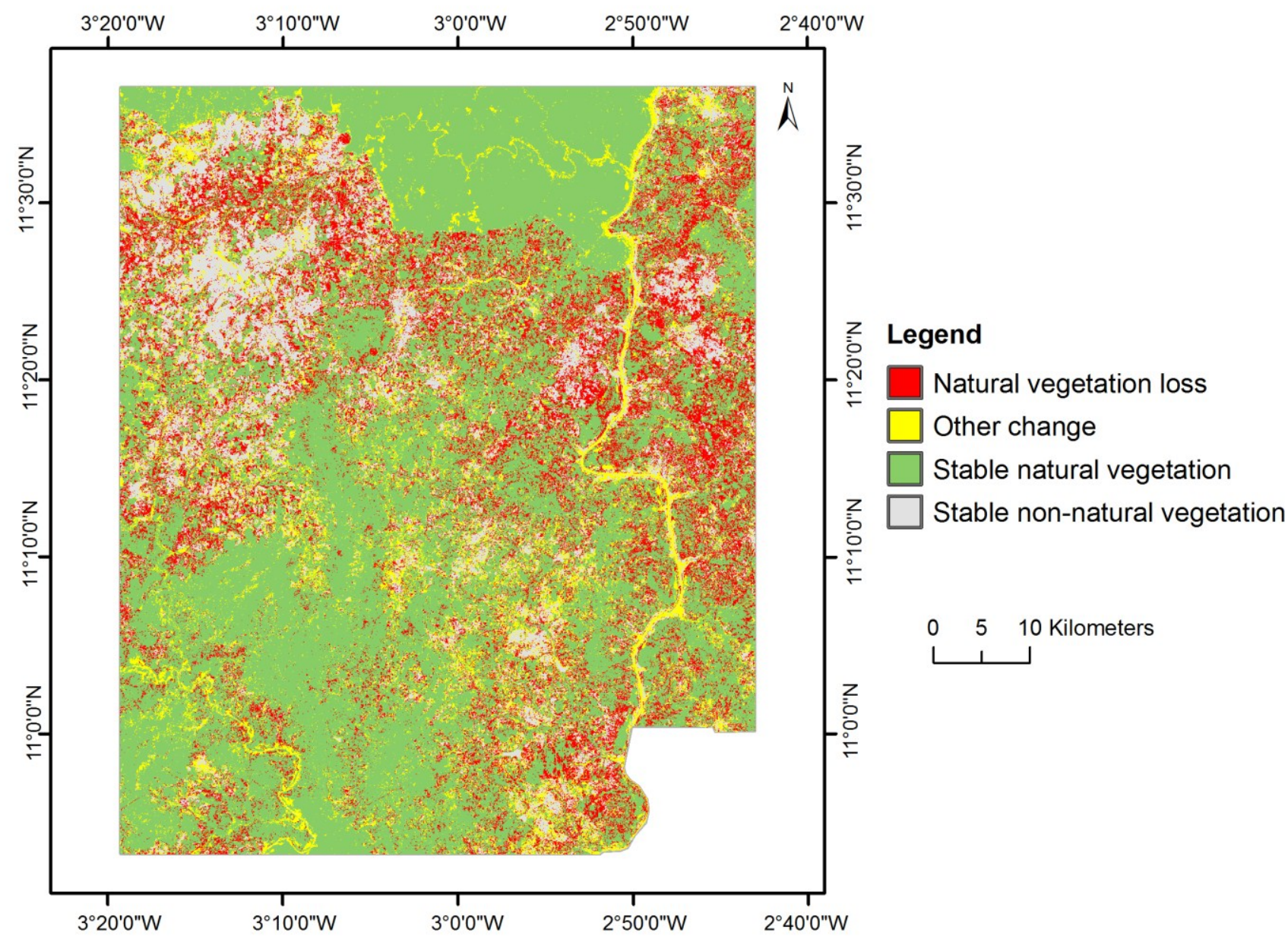

Figure 5. Distribution of LULCC in the study area between 1999 and 2011.

The main LULC conversions observed between 1999 and 2011 (Table 20) consisted of changes from woodland to agricultural area (occurred on $8.6 \%$ of the study area), woodland to mixed vegetation $(8.4 \%)$, mixed vegetation to woodland (7.2\%) and mixed vegetation to agricultural area (6.8\%). Stable LULC are dominated by woodland, mixed vegetation and agricultural area, which covered $24.1 \%, 17.8 \%$ and $13.8 \%$ of the area, respectively. Although there was an important loss of natural vegetation $(17.9 \% \pm 2.5 \%)$ in the study area, the transfer matrix highlighted that also regrowth of natural vegetation was recorded. As example, $2.7 \%, 4.5 \%$ and $0.8 \%$ of the study area were converted from agricultural area to woodland, agricultural area to mixed vegetation and bare surface to mixed vegetation, respectively. Those conversions could be cropland left under fallow, and potentially the result of reforestation and afforestation campaigns that are frequent in this area. 
Table 20. LULC transfer matrix between 1999 and 2011 expressed as percentage of area.

\begin{tabular}{|c|c|c|c|c|c|c|c|}
\hline & & \multicolumn{6}{|c|}{2011} \\
\hline & & Water & Woodland & $\begin{array}{c}\text { Bare } \\
\text { Surfaces }\end{array}$ & Mixed Veg. & Agric. Area & Area 1999 \\
\hline \multirow{6}{*}{ बे } & Water & 0.2 & 1.1 & 0 & 0.1 & 0.3 & 1.7 \\
\hline & Woodland & 0 & 24.1 & 0.4 & 8.4 & 8.6 & 41.5 \\
\hline & Bare surfaces & 0 & 0.2 & 0.3 & 0.8 & 0.5 & 1.8 \\
\hline & Mixed veg. & 0.01 & 7.2 & 1.4 & 17.8 & 6.8 & 33.2 \\
\hline & Agric. Area & 0 & 2.7 & 0.8 & 4.5 & 13.8 & 21.8 \\
\hline & Area 2011 & 0.2 & 35.3 & 2.9 & 31.6 & 30 & 100 \\
\hline
\end{tabular}

\section{Discussion}

\subsection{LULC Classification}

The use of late rainy season image (e.g., October image) was found more suitable than single image from other seasons (mid rainy, early rainy and dry seasons) for LULC classification in the Sudanese savannah of southwest BF. This is due the fact that late rainy season image provides better spectral information to separate confusing LULC classes such as agricultural area and natural vegetation. Medicinal, sacred, and fruit trees maintained in croplands creating intermixed areas (Figure 6) can be seen as one major reason for this spectral confusion between these two classes in the study region.

The result obtained for the Sudanese savannah are in agreement with the study by Lunetta and Balogh [10] and Key et al. [14], who noticed an improvement in LULC classification accuracy when they used multi-temporal images as compared to mono-temporal. However, findings in this study are in contrast with those reported in Langley et al. [19]. This is because the study by Langley et al. [19] focused on areas dominated by grassland located in the Jornada del Muerto plain of southern New Mexico, while the present work investigated an area dominated by woodland and mixed vegetation with many patterns of agricultural areas. These findings therefore highlight that differences in environment and LULC types might play a critical role.

Multi-temporal classification enables the analysis of images acquired at different phenological stages, which adds useful information for the classification, and in turn permits a better class discrimination. It has to be noted that this research did not assess different multi-temporal image compositions, like various combinations of months, which could be helpful for the choice of adequate temporal images [47,48]. However, the mono-temporal results strongly indicate that for multi-temporal mapping, the inclusion of late rainy season images is of relevance for accurate LULC mapping in southwest Burkina Faso. The remaining challenge is that frequent cloud cover in the region may reduce the availability of data in such important temporal windows suitable for classification [49].

In the face of frequently disturbed atmospheric conditions and poor availability of cloud-free satellite data in the study region, it is of high interest that ancillary data can significantly improve LULC classification to almost the same accuracy level as multi-temporal classifications. In the study area for instance, natural vegetation distribution (e.g., Woodland) is influenced by topography [13]. This explains the usefulness of including environmental variables into LULC discrimination especially elevation and geomorphology units that added most inputs to the classification after the remotely sensed infrared 
bands. These results confirm similar conclusions of previous studies, which utilized the environmental settings as add-on for an improved classification. Sesnie et al. [15] found the overall accuracy increasing from $82.4 \%$ to $87.4 \%$ with the addition of terrain variables (e.g., elevation and slope) in the classification of nine land cover types in Nicaraguan tropical dry forest. For monitoring of land-cover change in San Diego County, Rogan et al. [11] noted that ancillary variables (elevation, fire history, and Slope) contributed $15 \%$ to the overall accuracy of land-cover change mapping.

The most accurate classification was achieved when multi-temporal images and ancillary data were combined. The accuracy of this approach significantly differed from mono-temporal classification (as shown by the McNemar tests at the $95 \%$ confidence level), but not from classification results using a combination of specific mono-temporal image with ancillary data. This again shows that combining mono-temporal satellite data with information about environmental settings can be assessed to be a suitable alternative even in the heterogeneous savannah of southwest Burkina Faso.

The ancillary data showed positive impact on the classification results, but it needs to be stated that geomorphology and soil data, were produced at a scale of 1:500,000, which is at a coarse spatial resolution in comparison to $30 \mathrm{~m}$ Landsat pixels. The use of higher spatial resolution data matching the satellite data pixel could possibly improve the accuracy of LULC classifications. In general, LULC/LULCC maps presented in this study can be seen as a valuable input for training and validating global or regional LULC maps, which in turn will be used for regional assessments e.g. of the carbon budget [50]. Local maps are of particular value within the very complex landscape of West Africa, which extremely challenges the accurateness of existing regional to global maps [51]. Assessing the accuracy of regional maps requires an estimation of error propagation and hence documented quality information about the local input maps. The maps presented here, have such quality attributes even though it must be stated that validation was carried out on only $28.5 \%$ of the study area. For applying the validation throughout the study area, the availability of more high-resolution data sets would be desirable. With the increasing number of high-resolution data sources (e.g., QuickBird, RapidEye and Ikonos), future studies will potentially consider larger portions of their study area for accuracy assessment, which may give more confidence to the results. However, for instance validation activities of other LULC mapping studies relying on field observations can usually cover only those parts of the study areas which can be accessed either by car or by bike (e.g., [13]), which also questions the spatial distribution of the samples and hence the overall validity of the accuracy assessment. However, a validated LULC map based on some portions of the study area remains more reliable than a non-validated LULC map as observed in previous studies conducted in West Africa (e.g., [21]).

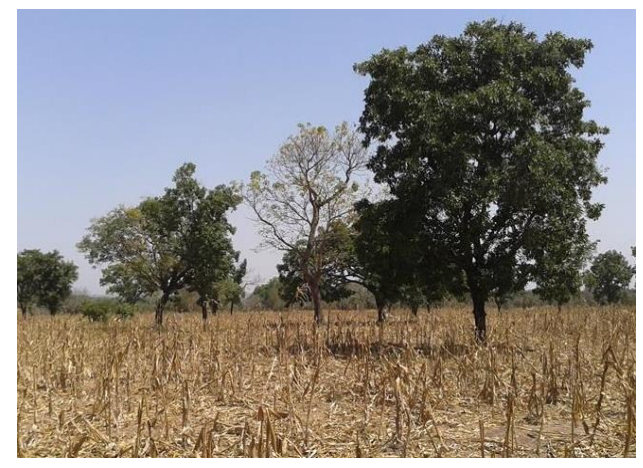

Figure 6. Harvested crop intermixed with trees in the study area. 


\subsection{LULCC in the Study Area}

Availability of adequate reference data provided a unique baseline for conducting LULCC map accuracy assessment in southwestern Burkina Faso. The observed changes of LULC in the study area were characterized by the increase in agricultural area and bare surface at the expense of natural vegetation (mixed vegetation and woodland). These dynamics attest to the ongoing deforestation in the southwest of Burkina Faso. Human activities are the main drivers of these changes in LULC, because in this region, where farming is characterized by low inputs such as fertilizers, farms are usually expanded and scattered across the landscape to increase yield [52]. Such a practice combined with population growth could explain the conversion of relatively huge areas of natural vegetation to agricultural area, as was observed in the period from 1999 to 2011. This conversion was also noticed elsewhere in the Sudanese savannah (e.g., [17,18,22]). Besides, in this region, fallowing practice has been reduced [53] leading to excessive cultivation of the same land over many years resulting in soil fertility loss, which favors the augmentation of bare surface. Furthermore, expansion of human settlement across the study area, as in Diebougou, Dano, Fara and Dissin, could also be a contributory factor to increasing bare surface at the expense of natural vegetation. Apart from agriculture and urban growth, other anthropogenic activities, such as wood harvesting for charcoal production, bushfire and mining, contribute to deforestation in the study area (Figure 7).

The loss of natural vegetation could have also been exacerbated by climate variability, which acts as a catalyst to the anthropogenic pressure. Indeed, in West Africa, IPCC [54] reported that climate change has increased rainfall variability and the recurrence of extreme events such as droughts. Figure 8 shows the temporal variability of rainfall (1981-2012) in the study area where the red bars indicates deficit of water and the blue represents the surplus of water. Three out of four stations (Fara, Diebougou and Dissin) highlighted that the years 1999 and 2006 were more humid than 2011. In addition, the year 1999 was characterized by floods in the southwest of Burkina Faso [55]. This further buttress the observed increase in bare surface in 2011 compared to 2006 and 1999. In fact, in this region, a decrease in rainfall leads to an increase in barren land area [12], mainly due to the close relationship between rainfall variability and vegetation dynamics [56].

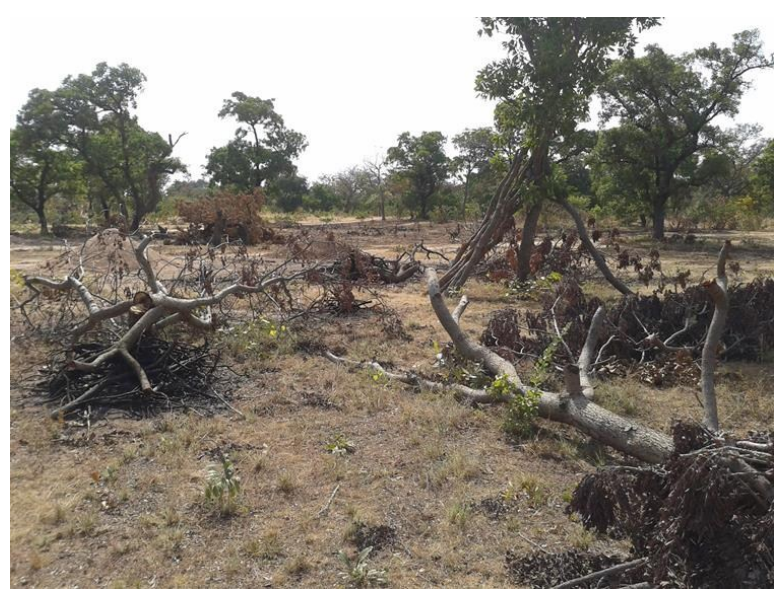

(a)

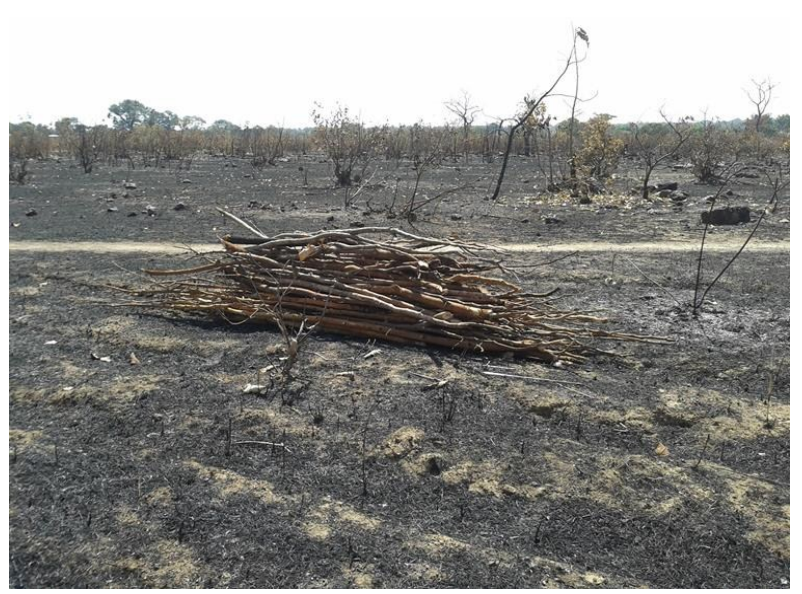

(b)

Figure 7. (a) Trees cut for new cropland; and (b) fuel wood collected in an area devastated by bushfire. 

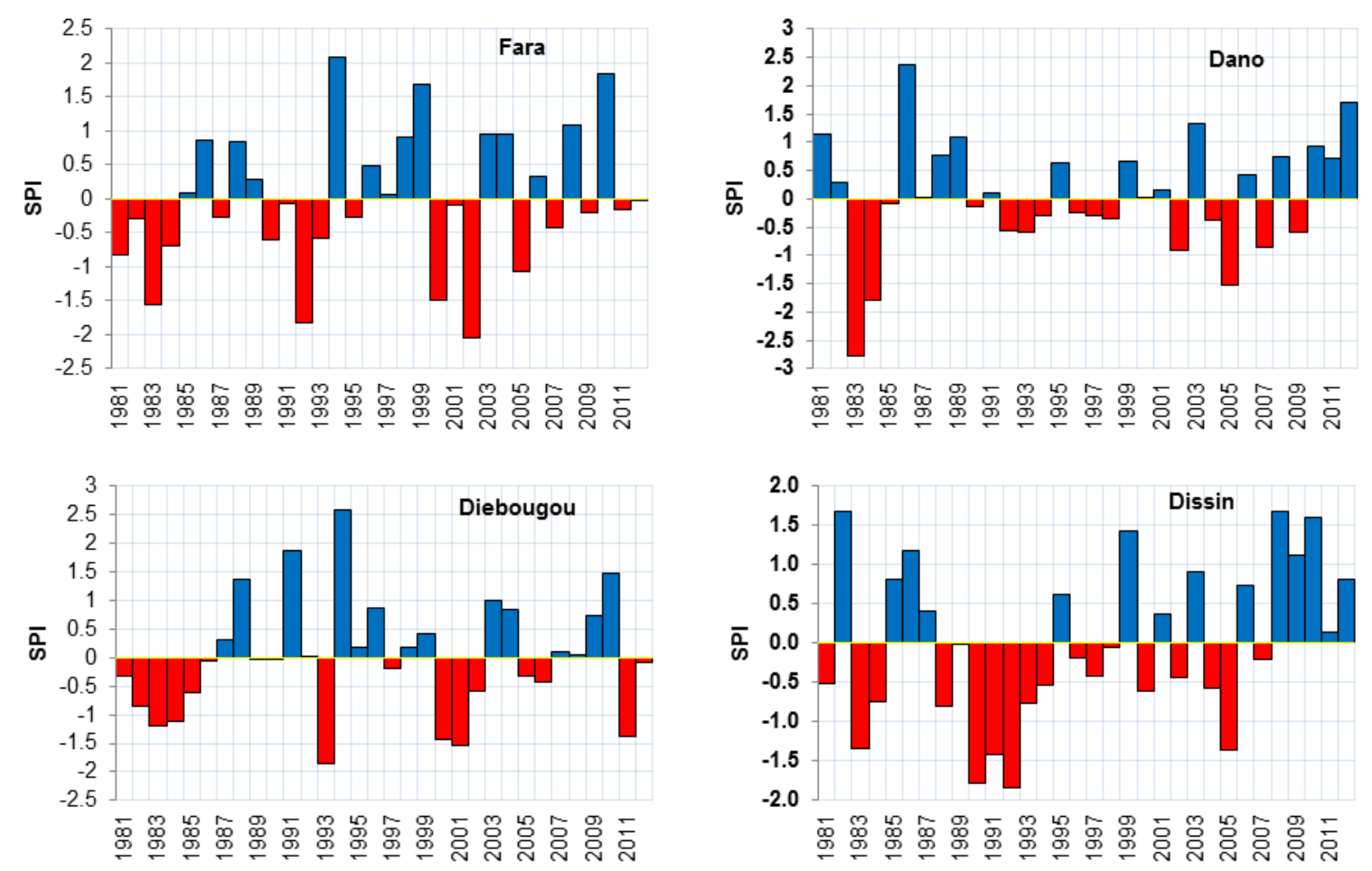

Figure 8. Rainfall variability in the study area (1981-2012) expressed as standardized precipitation index (SPI) distribution (Rainfall data collected from the national direction of meteorology of Burkina Faso).

\section{Conclusions}

This study, carried out in the Sudanese savannah of southwest Burkina Faso, compared mono-temporal and multi-temporal classification as well as their combination with ancillary data to determine the best classification method in order to produce an accurate post-classification LULCC map. In the study region, late rainy season images, used as input to a RF classifier algorithm, produced higher overall accuracy $(88 \%)$ than images from other periods. Multi-temporal classification significantly improved mono-temporal classification of LULC in terms of overall and class-wise accuracies. It was found that the overall accuracy increased from $88 \%$ to $94 \%$, the average user's from $87 \%$ to $93 \%$, and the average producer's from $86 \%$ to $91 \%$. The inclusion of ancillary data was found beneficial for multi-temporal classifications and also enhances mono-temporal classification accuracies to the level of multi-temporal classifications (94\%). Among the ancillary data (elevation, geomorphology, slope and soil types), elevation and geomorphology were found to be the most contributors to LULC classification in the study area. The results suggest that, at least for the heterogeneous Sudanese savannah of southwest Burkina Faso, the inclusion of ancillary data reduces the data requirements for accurate LULC/LULCC maps, where atmospheric conditions are the limiting factors for the availability of multi-temporal data. However, at least a cloud-free satellite data set from late rainy season period should be available for successful mapping. Of course, this method needs to be tested in other regions not only within the Sudanese savannah for a more generalized assessment of its performance and spatial transferability to LULC/LULCC maps in West Africa and beyond. 
The study also found unsustainable LULC dynamics within the savannah of southwest Burkina Faso, which is characterized by increasing agricultural area and bare surface at the detriment of woodland and mixed vegetation. For instance, between 1999 and 2011, agricultural area increased from $22.6 \% \pm 2.3 \%$ to $29.7 \% \pm 1.6 \%$, and contrary, woodland and mixed vegetation decreased from $40.1 \% \pm 2.0 \%$ to $36.4 \% \pm 2.1 \%$ and from $33.2 \% \pm 2.3 \%$ to $30.4 \% \pm 1.3 \%$, respectively. The LULCC map produced an overall accuracy of $92 \%$ and the loss of natural vegetation was estimated to be $17.9 \% \pm 2.5 \%$ in the period 1999-2011. Human activities are supposed to be the main drivers of the observed changes in LULC, but rainfall variability most probably also contributed to the observed LULCC. The loss of natural vegetation increases carbon emission in the atmosphere and could accelerate the process of land degradation in the study area. Of course, bi-temporal comparisons cannot attribute all observed alterations to land use change but can be seen as indicators of ongoing developments. Trend analysis of vegetation cover such as those obtained from moderate resolution time series (e.g., Moderate-Resolution Imaging Spectroradiometer, MODIS) can substantiate the hints of the high-resolution change map and allows for better assessment of intra-annual variability of vegetation cover, e.g., due to climate variability within the change analysis. However, the LULCC maps presented in this study can successfully support monitoring of ongoing reforestation activities. It can also be used to locate areas where adequate measures, for more efficient and sustainable land use management, can be introduced to safeguard the natural environment and livelihood of local population in the southwest Burkina Faso.

\section{Acknowledgments}

This study forms part of a $\mathrm{PhD}$ research performed within the WASCAL (West African Science Service Center on Climate Change and Adapted Land use) program on Climate Change and Land Use, which is funded by the German Federal Ministry for Education and Research (BMBF) and hosted by the Kwame Nkrumah University of Science and Technology of Kumasi, Ghana. This publication was funded by the German Research Foundation (DFG), and the University of Wuerzburg in the funding program Open Access Publishing. Special thanks to the Remote Sensing Unit at the Institute of Geography and Geology of the University of Wuerzburg (Germany) for providing satellite images. Finally, we are grateful to all the reviewers for their relevant comments and suggestions that helped to improve the quality of this paper.

\section{Author Contributions}

This research has been designed by Benewinde J-B, Zoungrana, Christopher Conrad, Leonard K. Amekudzi and Evariste Dapola Da. They processed the data with help and suggestions from Michael Thiel, Gerald Forkuor and Fabian Low. The manuscript was written and revised by Benewinde J-B. Zoungrana with input from all coauthors.

\section{Conflicts of Interest}

Authors declare no conflict of interest. 


\section{References}

1. Lambin, E.F. Modeling and monitoring land-cover change processes in tropical regions. Prog. Phys. Geogr. 1997, 21, 375-393.

2. Sala, O.E.; Chapin, F.S.; Armesto, J.J.; Berlow, E.; Bloomfield, J.; Dirzo, R.; Huber-Sanwald, E.; Huenneke, L.F.; Jackson,R.B.; Kinzig, A.; et al. Global biodiversity scenarios for the year 2100. Science 2000, 287, 1770-1774.

3. Chase, T.N.; Pielke, R.A.; Kittel, T.G.F.; Nemani, R.R.; Running, S.W. Simulated impacts of historical land cover changes on global climate in northern winter. Clim. Dyn. 1999, 16, 93-105.

4. Houghton, R.A.; Hackler, J.L.; Lawrence, K.T. The U.S. carbon budget: Contribution from land-use change. Science 1999, 285, 574-578.

5. Vitousek, P.M.; Mooney, H.A.; Lubchenco, J.; Melillo, J.M. Human domination of earth's ecosystems. Science 1997, 277, 494-499.

6. Duadze, S.E.K. Land Use and Land Cover Study of the Savannah Ecosystem in the Upper West Region (Ghana) Using Remote Sensing; Cuvillier Verlag: Göttingenn, Germany, 2004.

7. Di Gregorio, A.D.; Jansen, L.J. Land Cover Classification System, Classification Concepts and User Manual, Software Version2; Food and Agriculture Organization of the United Nations: Rome, Italy, 2005.

8. Blanzieri, E.; Melgani, F. Nearest neighbor classification of remote sensing images with the maximal margin principle. IEEE Trans. Geosci. Remote Sens. 2008, 46, 1804-1811.

9. Shalaby, A.; Tateishi, R. Remote sensing and GIS for mapping and monitoring land cover and land-use changes in the Northwestern coastal zone of Egypt. Appl. Geogr. 2007, 27, 28-41.

10. Lunetta, R.S.; Balogh, M.E. Application of multi-temporal Landsat 5 TM imagery for wetland identification. Photogramm. Eng. Remote Sens. 1999, 65, 1303-1310.

11. Rogan, J.; Miller, J.; Stow, D.; Franklin, J.; Levien, L.; Fischer, C. Land-cover change monitoring with classification trees using landsat TM and ancillary data. Photogramm. Eng. Remote Sens. 2003, 69, 793-804.

12. Ouedraogo, I.; Runge, J.; Eisenberg, J.; Barron, J.; Sawadogo. S. The re-greening of the Sahel: Natural cyclicity or human-induced change? Land 2014, 3, 1075-1090.

13. Cord, A.; Conrad, C.; Schmidt, M.; Dech, S. Standardized FAO-LCCS land cover mapping in heterogeneous tree savannas of West Africa. J. Arid Environ. 2010, 74, 1083-1091.

14. Key, T.; Warner, T.A.; McGraw, J.B.; Fajvan, M.A.F. A comparison of multispectral and multitemporal information in high spatial resolution imagery for classification of individual tree species in a temperate hardwood forest. Remote Sens. Environ. 2001, 75, 100-112.

15. Sesnie, S.E.; Hagell, S.E.; Otterstrom, S.M.; Chambers, C.L.; Dickson B.G. SRTM-DEM and landsat ETM+ data for mapping tropical dry forest cover and biodiversity assessment in Nicaragua. Rev. Geogr. Acad. 2008, 2, 53-65.

16. Trietz, P.; Howarth, P. Integrating spectral, spatial and terrain variables for forest ecosystem classification. Photogramm. Eng. Remote Sens. 2000, 66, 305-317.

17. Ouedraogo, I.; Tigabu, M.; Savadogo, P.; Compaore, H.; Oden, P.C.; Ouadba, J.M. Land cover change and its relation with population dynamics in Burkina Faso, West Africa. Land Degrad. Dev. 2010, 21, 453-462. 
18. Houessou, L.G.; Teka, O.; Imorou, I.T.; Lykke, A.M.; Sinsin, B. Land use and Land-cover change at "W" Biosphere Reserve and its surroundings areas in Benin Republic (West Africa). Environ. Nat. Resour. Res. 2013, 3, 87-101.

19. Langley, S.K.L.; Cheshire, H.M.; Humes, K.S. A comparison of single date and multitemporal satellite image classifications in a semi-arid grassland. J. Arid Environ. 2001, 49, 401-411.

20. Mickelson, J.G., Jr.; Civco, D.L.; Silander, J.A. Jr. Delineating forest canopy species in the northeastern United States using multi-temporal TM imagery. Photogramm. Eng. Remote Sens. 1998, 64, 891-904.

21. Aduah, M.S.; Aabeyir, R. Land cover dynamics in WA municipality, upper west region of Ghana. Res. J. Environ. Earth Sci. 2012, 4, 658-664.

22. Braimoh, A.K. Seasonal migration and land-use change in Ghana. Land Degrad. Dev. 2004, 15, $37-47$.

23. Ruelland, D.; Dezetter, A.; Puech, C.; Ardoin-Bardin, S. Long-term monitoring of land cover changes based on Landsat imagery to improve hydrological modelling in West Africa. Int. J. Remote Sens. 2008, 29, 3533-3551.

24. Reenberg, A.; Oksen, P.; Svendsen, J. Landuse changes vis-à-vis agricultural development in southeastern Burkina Faso: The field expansion dilemma. Geogr. Tidsskr. Dan. J. Geogr. 2003, $103,57-69$.

25. Yuan, J.; Niu, Z. Evaluation of atmospheric correction using FLAASH. In Proceedings of the Earth Observation and Remote Sensing Applications, Beijing, China, June 30-July 22008.

26. Atmospheric Correction Module: QUAC and FLAASH User's Guide, Version 4.7. Available online: https://www.exelisvis.com/portals/0/pdfs/envi/Flaash_Module.pdf (accessed on 1 July 2015).

27. Land cover classification system (LCCS): classification concepts and user manual. Available online: http://www.fao.org/docrep/003/x0596e/x0596e00.HTM (accessed on 1 July 2015).

28. Breiman, L. Random forests. Mach. Learn. 2001, 45, 5-32.

29. Rodriguez-Galiano, V.F.; Chica-Olmo, M.; Abarca-Hernandez, F.; Atkinson, P.M.; Jeganathan, C. Random Forest classification of Mediterranean land cover using multi-seasonal imagery and multi-seasonal texture. Remote Sens. Environ. 2012, 121, 93-107.

30. Mellor, A.; Haywood, A.; Stone, C.; Jones, S. The performance of random forests in an operational setting for large area sclerophyll forest classification. Remote Sens. 2013, 5, 2838-2856.

31. Akar, O.; Güngör, O. Classification of multispectral images using Random Forest algorithm. J. Geod. Geoinf. 2013, 1, 105-112.

32. Waske, B.; Braun, M. Classifier ensembles for land cover mapping using multi temporal SAR imagery. ISPRS J. Photogramm. Remote Sens. 2009, 64, 450-457.

33. Löw, F.; Conrad, C.; Michel, U. Decision fusion and non-parametric classifiers for land use mapping using multi-temporal RapidEye data. ISPRS J. Photogramm. Remote Sens. 2015, doi: 10.1016/j.isprsjprs.2015.07.001.

34. Rodriguez-Galiano, V.F.; Ghimire, B.; Rogan, J.; Chica-Olmo, M.; Rigol-Sanchez, J.P. An assessment of the effectiveness of a random forest classifier for land-cover classification. ISPRS J. Photogramm. Remote Sens. 2012, 67, 93-104.

35. Breiman, L. Bagging predictors. Mach. Learn. 1996, 24, 123-140.

36. Liaw A.; Wiener M. Classification and regression by random Forest. R News 2002, 2, 18-22. 
37. Horning, N. Random forests: An algorithm for image classification and generation of continuous fields data sets. In Proceedings of the International Conference on Geoinformatics for Spatial Infrastructure Development in Earth and Allied Sciences, Osaka, Japan, 9-11 December 2010.

38. Gislason, P.O.; Benediktsson, J.A.; Sveinsson, J.R. Random Forests for land cover classification. Pattern Recognit. Lett. 2006, 27, 294-300.

39. Nicodemus, K.K. Letter to the editor: On the stability and ranking of predictors from random forest variable importance measures. Brief. Bioinform. 2011, 12, 369-373.

40. Olofsson, P.; Foody, G.M.; Heroldc, M.; Stehman, S.V.; Woodcock, C.E.; Wulder, M.A. Good practices for estimating area and assessing accuracy of land change. Remote Sens. Environ. 2014, 148, 42-57.

41. Stehman, S.V.; Czaplewski, R.L. Design and analysis for thematic map accuracy assessment: Fundamental principles. Remote Sens. Environ. 1998, 64, 331-344.

42. Olofsson, P.; Foody, G.M.; Stehman, S.V.; Woodcock, C.E. Making better use of accuracy data in land change studies: Estimating accuracy and area and quantifying uncertainty using stratified estimation. Remote Sens. Environ. 2013, 129, 122-131.

43. Stehman, S.V. Impact of sample size allocation when using stratified random sampling to estimate accuracy and area of land-cover change. Remote Sens. Lett. 2012, 3, 111-120.

44. Congalton, R.G.; Green, K. Assessing the Accuracy of Remotely Sensed Data: Principles and Practices; CRC Press: London, UK, 2009.

45. Mas, J.F.; Pérez-Vega, A.; Ghilardi, A.; Martínez, S.; Loya-Carrillo, J.O.; Vega, E. A suite of tools for assessing thematic map accuracy. Geogr. J. 2014, doi:10.1155/2014/372349.

46. Manandhar, R.; Odeh, I.O.A.; Ancev, T. Improving the accuracy of land use and land cover classification of Landsat data using post-classification enhancement. Remote Sens. 2009, 1, 330-344.

47. Förster, M.; Schmidt, T.; Schuster, C.; Kleinschmit, B. Multi-temporal detection of grassland vegetation with RapidEye imagery and a spectral-temporal library. IEEE Geosci. Remote Sens. Symp. 2012, 4930-4933.

48. Conrad, C.; Dech, S.; Dubovyk, C.; Fritsch, S.; Klein, D.; Löw, F.; Schorcht , G.; Zeidler, J. Derivation of temporal windows for accurate crop discrimination in heterogeneous croplands of Uzbekistan using multitemporal RapidEye images. Comput. Electron. Agr. 2014, 103, 63-74.

49. Forkuor, G.; Conrad, C.; Thiel, M.; Ullmann, T.; Zoungrana, E. Integration of optical and Synthetic Aperture Radar imagery for improving crop mapping in Northwestern Benin, West Africa. Remote Sens. 2014, 6, 6472-6499.

50. Machwitz, M.; Gessner, U.; Conrad, C.; Falk, U.; Richters, J.; Dech, S.; Modelling the gross primary productivity of West Africa with the regional biomass model RBM+, using optimized $250 \mathrm{~m}$ MODIS FPAR and fractional vegetation cover information. Int. J. Appl. Earth Obs. 2015, doi:10.1016/j.jag.2015.04.007.

51. Herold, M.; Woodcock, C.E.; Loveland, T.R.; Townshend, J.; Brady, M.; Steenmans, C.; Schmullius, C.C. Land-cover observations as part of a Global Earth Observation System of Systems (GEOSS): Progress, Activities, and prospects. IEEE Syst. J. 2008, 2, 414-423.

52. Boateng, P.K. Agricultural production, land-use/cover change and the desertification debate in the West African Savannah: An adapted political ecology approach. J. Arts Hum. 2013, 2, 21-35. 
53. Bado, B.V.; Bationo, A.; Lompo, F.; Traore, K.; Sedogo, M.P.; Cescas, M.P. Long term effects of crop rotations with fallow or groundnut on soil fertility and succeeding sorghum yields in the Guinea Savannah of West Africa. In Lessons learned from Long-term Soil Fertility Management Experiments in Africa; Springer Netherlands; Berlin, Germany, 2012; pp. 27-40.

54. Intergovernmental Panel on Climate Change. IPCC Fourth Assessment Report: Climate Change 2007; Intergovernmental Panel on Climate Change: Geneva, Switzerland, 2007.

55. Sahel Weather and Crop Situation 1999, Global Information and Early Warning System on Food and agriculture, Report No 4. Available online: ftp://ftp.fao.org/docrep/fao/003/x3004e/ x3004e00.pdf (accessed on 1 July 2015).

56. Zoungrana, B.J.B.; Conrad, C.; Amekudzi, L.K.; Thiel, M.; Da, E.D. Land use/cover response to rainfall variability: A comparing analysis between NDVI and EVI in the Southwest of Burkina Faso. Climate 2015, 3, 63-77.

(C) 2015 by the authors; licensee MDPI, Basel, Switzerland. This article is an open access article distributed under the terms and conditions of the Creative Commons Attribution license (http://creativecommons.org/licenses/by/4.0/). 